\title{
Ventricular Fibrillation Resulting from Diaphragmatic Stimulation during Gastric Bypass Surgery
}

\author{
Christian Perzanowski \\ Arrhythmia and Clinical Research, Cape Fear Valley Medical Center, Fayetteville, NC, USA
}

\section{Key Words}

Cardiovascular disorders · Obesity $\cdot$ Bariatric surgery $\cdot$ Ventricular fibrillation

\begin{abstract}
Objective: Gastric bypass operations are common and severely obese patients are prone to arrhythmias, particularly atrial fibrillation. Intraoperative ventricular arrhythmias during bariatric surgery have not been reported previously. Case Report: A 35-year-old, severely obese, diabetic woman with no other prior medical history underwent thorough preoperative cardiovascular evaluation before having laparoscopic Roux-en-Y gastric bypass. Intraoperatively she developed sudden onset ventricular fibrillation during the use of unipolar electrocautery near the Angle of His. The procedure was aborted, and the patient underwent repeat cardiovascular assessment including coronary angiography and serial electrophysiology studies before being unremarkably re-operated 6 months later, at which time a harmonic scalpel was used for dissection. 12 months post operation, the patient remains asymptomatic. Conclusion: Owing to the proximity of the right ventricle overlying the diaphragm, far-field stimulation was likely responsible for inducing VF.

Copyright (c) 2012 S. Karger GmbH, Freiburg
\end{abstract}

\section{Introduction}

The number of obesity operations is rapidly increasing as safety is significantly improving [1]. Although obesity is a risk factor for arrhythmias [2], cardiomyopathy [3], and ischemic heart disease [4], intraoperative ventricular fibrillation during obesity surgery has never been reported. 
Perzanowski et al.: Ventricular Fibrillation Resulting from Diaphragmatic Stimulation during Gastric Bypass Surgery

\section{Case Report}

This report presents an unusual case of cautery-induced ventricular fibrillation (VF) in a 35-year-old, severely obese (BMI $52 \mathrm{~kg} / \mathrm{m}^{2}$ ), diabetic woman with unremarkable preoperative stress testing and cardiac echocardiography without evidence of intraoperative cardiac ischemia. During laparoscopic Roux-en-Y gastric bypass, the patient had sudden onset of VF coincident with the use of unipolar electrocautery near the Angle of His, and the procedure was aborted. She had no mitigating metabolic or pulmonary abnormalities.

During postoperative cardiac re-evaluation including coronary angiography, cardiac magnetic resonance imaging, and serial invasive electrophysiology studies 6 months apart, she did not exhibit any abnormalities and was non-inducible for arrhythmias. The mechanism for her VF was felt to be iatrogenic and related to the use of monopolar electrocautery near the right ventricle which may have led to far-field stimulation and VF, as has been described earlier during subdiaphragmatic electrocautery [5].

\section{Discussion}

The type of cautery used and the location of the dispersive pad may explain how this may have occurred. The most commonly used electrode configuration is unipolar where the dispersive electrode is a pad positioned on the back, shoulder, or thigh. Since current has direction, the location of the dispersive pad influences the vector and may lead to unintended delivery of electrical current to nearby anatomic structures. The use of unipolar cautery in the vicinity of the Angle of His as in this case raises the possibility that right ventricular myocardial tissue was electrostimulated. This complication is much less likely to occur with bipolar current $[6,7]$.

The role of epicardial fat may have a protective role in impeding electrical conductivity and may a reason for the rarity of this complication. Mathematical modeling has suggested reduced penetration of radiofrequency ablation of atrial tissue by overlying adipose tissue [8]. Clinical experience in the ablation of epicardial ventricular tachycardia has proven overlying adipose tissue to be a limiting factor in lesion formation, hence requiring greater power for effective ablation [9]. This case prompts further questions regarding the potential role of pericardial adipose tissue during obesity-related surgery.

\section{Disclosure Statement}

I have no conflicts of interest. Nothing to disclose.

\section{References}

1 Longitudinal Assessment of Bariatric Surgery (LABS) Consortium, Flum DR, Belle SH, King WC, et al: Perioperative safety in the longitudinal assessment of bariatric surgery. N Engl J Med 2009;361:445-454.

2 Dublin S, FrenchB, , Glazer NL, et al: Risk of new-onset atrial fibrillation in relation to body mass index, Arch Intern Med 2006;166:2322-2328.

3 Dela Cruz CS, Matthay RA: Role of obesity in cardiomyopathy and pulmonary hypertension. Clin Chest Med 2009;30:509-523.

4 Murphy NF, MacIntyre K, Stewart S, et al: Long-term cardiovascular consequences of obesity: 20-year follow-up of more than 15000 middle-aged men and women (the Renfrew-Paisley study). Eur Heart J 2006; 27:96-106. 
5 Yan CY, Cai XJ, Wang YF, Yu H: Ventricular fibrillation caused by electrocoagulation in monopolar mode during laparoscopic subphrenic mass resection. Surg Endosc 2011;25:309-311.

6 Talamini MA: Advanced Therapy in Minimally Invasive Surgery. Hamilton, Decker, 2006, pp 139-146.

7 Lo R, Mitrache A, Quan W, Cohen TJ: Electrocautery-induced ventricular tachycardia and fibrillation during device implantation and explantation. J Invasive Cardiol 2007;19:12-15.

8 Suárez AG, Hornero F, Berjano EJ: Mathematical modeling of epicardial RF ablation of atrial tissue with overlying epicardial fat. Open Biomed Eng J 2010;4:47-55.

- 9 d'Avila A, Houghtaling C, Gutierrez P, Vragovic O, Ruskin JN, Josephson ME, Reddy VY: Catheter ablation of ventricular epicardial tissue: a comparison of standard and cooled-tip radiofrequency energy. Circulation. 200418;109:2363-2369. 